\title{
Changing Dynamics of Team Leadership in Global Project Environments
}

\author{
Hans J. Thamhain
}

Management Department, Bentley University, Waltham, USA.

Email: hthamhain@bentley.edu

Received October $10^{\text {th }}, 2012$; revised November $20^{\text {th }}, 2012$; accepted December $17^{\text {th }}, 2012$

Copyright (C) 2013 Hans J. Thamhain. This is an open access article distributed under the Creative Commons Attribution License, which permits unrestricted use, distribution, and reproduction in any medium, provided the original work is properly cited.

\begin{abstract}
The dynamics and challenges of managing geographically dispersed project teams is examined in a field investigation of 72 multinational product developments, observed and studied between 2008 and 2012. The findings provide insight into the business processes and leadership style most conducive to cross-functional collaboration and effective project integration throughout the enterprise and its partners. The results show that many of the problems that surface on the technical side can be traced to social, psychological and organizational issues. In fact, people issues have the strongest impact on project performance. People are an intricate part of the work process. Issues affecting people, eventually impact the broader enterprise. On the positive side, the study shows that certain conditions, such as personal interest, pride and satisfaction with the work, professional work challenge, accomplishments and recognition, serve as catalysts toward unifying culturally diverse project teams and their work processes. These conditions act as bridging mechanisms between organizational goals and personal interests, between central control and local management norms, and between following a project plan and adaptive problem solving. However, working seamless across borders and cultures requires more than just issuing work orders, project summary plans or management guidelines. Emphasis must be on common values and goals to focus and unify the team. By recognizing the greater autonomy of all international partners as well as their cultural differences, management can build a true partnership among all the contributing organizations with strong linkages for communication, decision making and technology transfer that is sustainable over the project lifecycle. The paper suggests a framework for managerial actions and leadership for building high-performance multinational project teams.
\end{abstract}

Keywords: Project Management; Multinational Team Leadership; Technology; Virtual Enterprise

\section{Introduction}

Multinational Projects, a New Frontier. In today's connected, hyper-competitive world, most project teams must function in an environment that interacts with joint ventures, alliances, multinational sourcing and intricate vendor relations. Projects are complex in nature and imbedded in lots of technology. We find these operationally complex team environments in virtually every segment of industry and government. Whether Yahoo creates a new search engine, Sony develops a new laptop computer, or the World Health Organization rolls out a new information system, success depends to a large degree on effective interactions among the team members responsible for the new development. This includes support groups, subcontractors, vendors, partners, government agencies, customer organizations and other project stakeholders [1-6]. Much has been written about the chal- lenges and how the digital age has affected our business environment. Globalization, privatization, digitization and rapidly changing technologies have transformed our economies into a hyper-competitive enterprise system where virtually every organization is under pressure to do more things faster, better and cheaper.

Few managers would disagree, team leadership is critically important to project performance and essential for competing effectively in today's global arena, a notion that finds also strong support among management researchers [7-10]. However, building and managing a workgroup as a fully integrated, unified team is a daunting task with strong implications on business performance [11-15]. It is also a highly intricate process that is difficult to analyze and to understand. Scholars, such as [1-3,10,14,16-20] have studied project teams extensively, root-causing their successes and failures, and identifying 
organizational conditions for effective teamwork [16,2123]. As a result we have gained sophisticated knowledge and substantial insight into the effects and organizational dynamics of managing project teams. Yet, relatively little is known about the effectiveness of team leadership styles and the organizational conditions most conducive to team performance in project environments that are geographically dispersed across national borders, operating in technological complex, culturally-diverse, multi-national environments, which is the focus of this paper.

The significance of this study is in the area of project management effectiveness. Building on the work of contemporary management researchers, this study provides insight into the team leadership style, and the organizational barriers, drivers and conditions most conducive to high team performance in multinational project environments. This is a very different environment in comparison to traditional, more centrally managed projects. Management direction must be "synthesized and orchestrated" centrally, but then translated across borders into the cultures of the local operations [24]. Linkages among individual work components need to be developed and effectively "managed" across geographic areas and organizational cultures. Hence, multinational project teams need to be integrated not only across the miles, but also be unified among different business processes, management styles, operational support systems, and organizational cultures [25]. This requires not only effective networking and cooperation among people from different organizations, support groups, subcontractors, vendors, government agencies, customer communities, and broadly based alliances across the enterprise and its international borders, but also the ability to deal with broad global issues of uncertainties and risks caused by economic, political, social, and regulatory factors.

\section{Project Management Today: A New Frontier}

\subsection{Forces that Shape the Project Environment}

We have seen major changes in the business environment, most pronounced over the past two decades that have shaped the competitive landscape and shifted the paradigm of project management, the way we organize, charter and lead our project teams today.

\subsection{Shift from Linear Processes to Dynamic Systems.}

Traditionally, management concepts were based predominately on linear models, typically exemplified by production lines, sequential product developments, scheduled services, and discovery-oriented R \& D. Today's more complex projects and dynamic business environ- ment requires a much more interactive management style to deal with complex sets of interrelated, nonlinear, and often difficult-to-define processes. To be effective, project leadership has become more sophisticated, relying strongly on group interaction, resource and power sharing, individual accountability, commitment, self-direction, and control. That is, contemporary management relies to a considerable extent on member-generated performance norms and evaluations, rather than on hierarchical guidelines, policies, and procedures. While this paradigm shift is driven by changing organizational complexities, capabilities, demands, and cultures, it also leads to a radical departures from traditional management philosophy on organizational structure, motivation, leadership, and project control. As a result, traditional "hardwired" organizations and processes are replaced by more flexible and nimble networks that are usually derivatives of the conventional matrix organization. However, these networks have more permeable boundaries, more power and resource sharing, and more concurrent operational processes.

\subsection{Shift from Efficiency toward Effectiveness}

Many companies have broadened their focus from efficient execution of their operations and projects-emphasizing job skills, teamwork, communications, and resource optimization at the operational level-to include organizational effectiveness. This shift responds to the need for better integration of ongoing activities and projects into the overall enterprise, making sure that "we are doing the right thing". As an example, companies are leveraging project management as a core competency, integrating project-oriented activities closely with other functions, such as marketing, R \& D, field services, and strategic business planning. While this shift is enhancing the status and value of certain business functions within the enterprise, it raises the overall level of responsibility and accountability, and puts higher demands on previously more autonomous functions, such as R \& D and product development, to perform as a full partner within the integrated enterprise system.

\subsection{Shift from Executing Projects to Enterprise-Wide Project Management}

Many companies use project management extensively today for far more than just implementing specific projects. These companies leverage the full capabilities of project management, enterprise-wide, as a core competency, achieving accelerated product developments, higher levels of innovation, better quality, and better overall resource utilization. To achieve this level of competency, project operations must be integrated with the strategic planning system and business processes across the total enterprise. Managerial focus has shifted from the me- 
chanics of controlling projects according to established schedules and budgets to optimizing desired results across a wide spectrum of performance measures that span the total enterprise.

\subsection{Shift from Managing Information to Fully Utilizing Information Technology}

Today's technology provides managers in any part of the enterprise with push-button access to critical information on operational status and performance. The availability and promise of technology has led to the development of an enormous variety of powerful IT-based tools and techniques, and the acquisition of these tools by managers at all levels. With the powerful promise for increasing operational effectiveness managers are eager to use these tools in support of their activities, ranging from resource estimating, to scheduling, risk analysis, and decision support.

\subsection{Shift from Managerial Control to Self-Direction and Accountability}

With increasing business complexities, advances in information technology, changing organizational cultures, and new market structures, companies look beyond traditional managerial control for effective execution of their projects, operations, and missions. Especially top-down controls, based on centralized command and communications, while critically important, are no longer sufficient for generating satisfactory results. Organizational activities are increasing project-oriented, relying on technology, innovation, cross-functional teamwork, and decision making, intricate multi-company alliances and highly complex forms of work integration. The dynamics of these environments create pressures toward membergenerated performance norms and work processes, and a shift toward more team ownership, empowerment, and self-control. All of this has a profound impact on the way managers must manage and lead, and analyze the work environment for effective intervention. The methods of communication, decision making, soliciting commitment, and risk sharing are constantly shifting away from a centralized, autocratic management style to a team-centered, more self-directed form of control.

A complex environment? Yes! But it is just the beginning of understanding the great challenges that managers face in our global businesses environment. It is a starting point understanding the interaction of organizational, behavioral, technical, and social variables that create the dynamics of this continuously changing landscape.

\section{Why Do We Need Multinational Project Teams?}

Given all of these challenges and issues it is not surpris- ing that some voices in the management community question the wisdom of spreading project teams across the globe. Even those who benefit from multinational resource utilization, often find it frustrating to deal with the challenges. Yet, in most cases there are few alternatives for companies that want to compete effectively in today's business environment. Few companies can accomplish all of their business activities in-house [26-29]. Whether Apple develops a new iPhone, Airbus rolls out a new aircraft or Rio de Janeiro builds a new Olympic stadium; from medical research to computer systems development, companies try to leverage their budgets and accelerate their schedules by forming alliances, consortia and partnerships with other firms, universities and government agencies. These collaborations range from simple cooperative agreements to "open innovation", a concept of scouting for new product and service ideas, anywhere in the world [30]. Other companies which operate globally as an enterprise, such as IBM, Boeing or Microsoft, often have their developments dispersed across international borders as part of their global business strategy. In today's connected world, companies can take advantage of multinational sourcing, joint ventures and alliances. They can access the best talent and benefit from most favorable cost and timing conditions anywhere, regardless of their geographic location. However, organizing and managing these globally dispersed teams towards desired results is an art and a science that involves great challenges, new work processes and business models, defining a new frontier of project management.

\section{Method}

The research reported here was conducted between 2008 and 2012 as part of my ongoing investigation into project management effectiveness with results regularly reported in the literature [30-32]. Building on my earlier research [33-37], which examined team member needs and the dynamics of work interfaces and interactions, the current research expands the investigation into the effects of leadership style and project environment on overall team performance in multinational project environments. The current field study includes 72 geographically dispersed, multinational new product development teams, working in 34 large enterprises of the "Fortune-500" category.

\subsection{Data Collection Method}

This three-phase field study includes 34 technologybased project organizations. Each organization conducted multiple projects as part of a large, "Fortune-500" type enterprise, operating in multinational environments. Specifically, $65 \%$ of the companies in the sample fall in to the Fortune-500 classification, 23\% are Fortune-1000 
companies, while the remainder includes smaller firms. However, none of the companies in the sample can be classified as small or medium size. For each of these organizations, the research was conducted in three stages. In the first stage, on-site observations and interviews with project leaders and project team personnel were conducted. This helped to 1) understand the specific nature and challenges of the project work undertaken, 2) prepare for the proper introduction of the questionnaire, and 3) design the follow-up interviews. During the second stage, data were collected as part of a management consulting or training assignment, using questionnaires, observations, and expert panels. The third stage relied mostly on in-depth retrospective interviewing, providing perspectives and additional information for clarifying and leveraging the data captured in stage one and two. This paper focuses on the results of the third stage, which was completed in 2009. The results are integrated with the previous findings of stage 1 and 2 providing the basis for the recommendations and conclusions of this paper. In addition to the interviews, the stage- 3 data collection includes other sources of relevant material, such as project progress reports, company reports, design review memos, committee action reports, financial statements and information from the public media.

The purpose of this combined three-stage data collection method was to leverage the information-gathering process for identifying the drivers and barriers to project team performance, and for gaining insight into its management process. This combined method is particularly useful for new and exploratory investigations, such as the study reported here, which is considerably outside the framework of well-established theories and constructs [38,39]. The format and process of the specific questionnaires and in-depth semi-structured interviews used in this study, was developed and tested in previous field studies of project management, similar in context to the current investigation [6,34-37,40].

\subsection{Data}

The unit of analysis used in this study is the project. The combined field study, conducted between 2008 and 2012, yielded data from 46 project teams with a total sample population of 525 project professionals such as engineers, scientists, and technicians, plus their managers, including 16 functional resource managers, 46 project team leaders, 16 product managers, 5 directors of $\mathrm{R} \& \mathrm{D}, 4$ directors of marketing, and 11 general management executives at the vice presidential level. Together, the data covered over 125 projects in 34 companies, spanning a total of 19 countries. The projects observed in this study involved mostly high-technology product/service-oriented developments and roll-outs, such as information system, financial services, automotive, airplane, computer and pharmaceutical products. Project budgets averaged \$1.2M and project lifecycles averaged 18 months. All project teams saw themselves working in a high-technology, multi-national, culturally diverse environment. The data were obtained from three sources, questionnaires, participant observation and in-depth retrospective interviewing, as discussed in the previous section. Specifically in Stage-Three, 138 interviews were held with team leaders, line managers, product managers, marketing directors and general management executives. These discussions provided interesting and useful insight into the issues and challenges of cross-functional integration necessary for successful technology transfer. The implications for multinational project management have been integrated with the Result Section of this paper.

\subsection{Data Analysis}

Standard statistical methods were used to evaluate and summarize the survey data of Stage-2 (cf. appendix for summary of Stage-2 results). Because many of the organizational and behavioral variables investigated contain ordinal measurements which do not follow normal distribution, distribution-free non-parametric methods, such as Kendall's Tau rank-order correlation and KruskalWallis analysis of variance by ranks, have been chosen to evaluate the survey data of Stage-Two.

Stage-Three utilizes mostly content analysis for evaluating the interviews and observations. In combination with the findings from Stage-2, the Stage-3 analysis allows us to go beyond the quantitative results of the statistical data analysis, and to synthesize some of the more interesting lessons learned from the broader context of the field research. The interviews, observations and follow-up discussions obtained during Stage-3 were especially useful in gleaning additional, deeper insight into the processes and challenges of working with culturally diverse project teams, and to identify implications for project leadership effectiveness.

\section{Results}

Some of the consistent and most striking findings from the quantitative analysis of Stage- 2 point are at the need for increasing involvement of all project stakeholders throughout the organization and its external partners. Table 1 summarizes the quantitative data of the field study. The correlation between variables of the team environment and team performance provides a snapshot of the critical importance of both human factors and traditional project management techniques to team performance. The 20 variables of the team environment are listed in order of importance to overall team performance. The presence and strength of these organizational variables was measured on a five-point scale as a perception 
Table 1. Team environment versus performance (Kendall's Tau rank-order correlation).

\begin{tabular}{|c|c|c|c|c|c|c|c|c|c|c|c|}
\hline \multirow[b]{2}{*}{ TEAM ENVIRONMENT ${ }^{*}$} & \multicolumn{11}{|c|}{ Team Characteristics and Performance } \\
\hline & 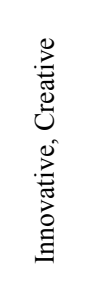 & 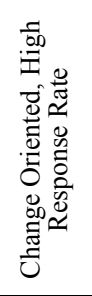 & 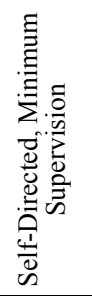 & 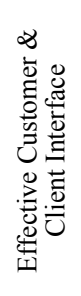 & 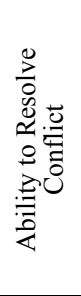 & 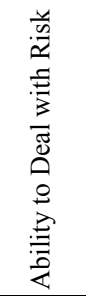 & 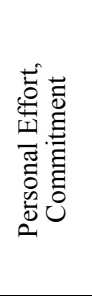 & 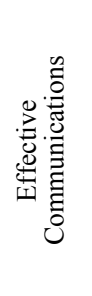 & 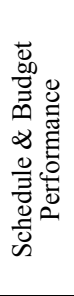 & 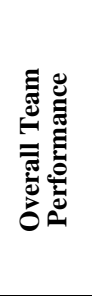 & 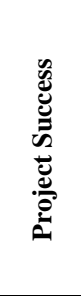 \\
\hline 1 Interesting Work & 0.42 & 0.30 & 0.43 & 0.27 & 0.27 & 0.39 & 0.43 & 0.35 & 0.37 & 0.45 & 0.42 \\
\hline 2 Recognition/Accomplish & 0.45 & 0.31 & 0.39 & 0.28 & 0.38 & 0.27 & 0.35 & 0.23 & 0.38 & 0.38 & 0.35 \\
\hline 3 Clear Organizat'l Objectives & 0.33 & 0.29 & 0.45 & 0.30 & 0.38 & 0.21 & 0.28 & 0.22 & 0.31 & 0.36 & 0.31 \\
\hline 4 Job Skills \& Expertise & 0.31 & 0.15 & 0.37 & 0.28 & 0.33 & 0.32 & 0.15 & 0.11 & 0.21 & 0.36 & 0.37 \\
\hline 5 Direction \& Leadership & 0.37 & 0.33 & 0.27 & 0.33 & 0.27 & 0.27 & 0.22 & 0.13 & 0.33 & 0.35 & 0.30 \\
\hline 6 Trust/Respect/Credibility & 0.35 & 0.44 & 0.36 & 0.27 & 0.43 & 0.08 & 0.40 & 0.38 & 0.27 & 0.30 & 0.28 \\
\hline 7 Cross-Functional Support & 0.29 & 0.12 & 0.29 & 0.23 & 0.38 & 0.37 & 0.28 & 0.47 & 0.25 & 0.27 & 0.29 \\
\hline 8 Clear Proj Plan \& Support & 0.36 & 0.20 & 0.35 & 0.40 & 0.36 & 0.36 & 0.36 & 0.29 & 0.40 & 0.25 & 0.36 \\
\hline 9 Autonomy \& Freedom & 0.38 & 0.14 & 0.42 & 0.28 & 0.15 & 0.34 & 0.36 & 0.23 & 0.23 & 0.23 & 0.21 \\
\hline 10 Career Development & 0.22 & 0.17 & 0.15 & 0.17 & 0.09 & 0.10 & 0.07 & 0.00 & 0.24 & 0.12 & 0.07 \\
\hline 11 Job Security & 0.25 & 0.29 & 0.13 & 0.19 & 0.26 & 0.30 & 0.12 & 0.12 & 0.31 & 0.12 & 0.22 \\
\hline 12 Salary/Raise/Bonuses & 0.09 & 0.18 & 0.05 & 0.07 & 0.07 & -0.09 & 0.12 & -0.03 & 0.20 & 0.15 & 0.09 \\
\hline 13 Compensatory Time & 0.10 & 0.13 & -0.09 & 0.02 & 0.00 & 0.04 & 0.09 & -0.05 & 0.12 & 0.15 & 0.03 \\
\hline 14 Project Visibility & 0.26 & 0.26 & 0.18 & 0.22 & 0.17 & 0.17 & 0.22 & 0.17 & 0.15 & 0.12 & 0.17 \\
\hline 15 Team Maturity/Tenure & 0.32 & 0.30 & 0.30 & 0.13 & 0.12 & 0.11 & 0.11 & 0.18 & 0.12 & 0.10 & 0.18 \\
\hline 16 Project Duration & -0.05 & -07 & 0.04 & 0.26 & 0.11 & -0.16 & 0.06 & 0.27 & 0.03 & -0.08 & 0.02 \\
\hline 17 Project Stability & -0.12 & -0.10 & 0.12 & -0.14 & 0.22 & 0.20 & 0.05 & 0.33 & 0.05 & -0.10 & -0.09 \\
\hline 18 Organizational Stability & -0.29 & 0.18 & 0.17 & -0.22 & 0.19 & 0.14 & -0.09 & 0.27 & -15 & -0.12 & -0.16 \\
\hline 19 Technological Complexity & 0.11 & 0.22 & 0.32 & 0.09 & -0.11 & -0.13 & -0.12 & 0.09 & 0.11 & -0.15 & -0.12 \\
\hline 20 Project Size/Complexity & -0.12 & 0.02 & -0.15 & -0.16 & 0.06 & 0.07 & -0.10 & -0.07 & 0.03 & -0.18 & -0.08 \\
\hline
\end{tabular}

All variables were measured with descriptive statements on a 5-point Likert scale: 1) strongly disagree, 2) disagree, 3) neutral, 4) agree, 5) strongly agree. Statistical Significance: $\mathrm{p}=0.10(\tau \geq 0.20), \mathrm{p}=0.05(\tau \geq 0.31), \mathrm{p}=0.01(\tau \geq 0.36)$; correlation significance of $\mathrm{p}=0.01$ or stronger marked bold. Negative correlations are marked in italics. ${ }^{*},{ }^{\#}$ Symbols: Statements to measure variables were judged by $\left[{ }^{*}\right]$ team member, $\left[{ }^{\#}\right]$ senior management.

of project team members, while team performance was measured as a judgment perception of senior management. Initially, the dataset was analyzed separately for each "local" team in its own cultural environment using Kendall-Tau correlation analysis as summarized in Table 1. Then, the cross-team association was tested via Kruskal-Wallis analysis of variance by rank which shows at a confidence level of $98 \%$ that an agreement exists among local teams on their rankings. That is, we can conclude that local teams and their managers come from the same population and therefore could be aggregated into one larger sample. This finding is interesting because it shows similarity among the various local teams in spite of their differences in culture. While specific interpretation and perception of environmental characteristics, such as "needs" and "professionally stimulating work," are differing among teams, the rank-order correlation to project performance metrics is similar. The significance of this finding for team leaders is the need for creating a work environment that is professionally conducive and stimulating to the project work in progress. This cannot be accomplished by procedures or formalities but requires palpable actions, earned credibility, trust and respect of the project manager.

\subsection{The Importance of Creating a High-Performance Team Environment}

It is interesting to note that the same conditions, which 
are conducive to overall team performance, also lead to 1) innovation and creative problem solving, 2) change orientation and high response rate of the team, 3) self-directed teams with minimum supervision, 4) effective customer \& client interface, 5) effective conflict resolution among team members, 6) ability to deal with risk and uncertainty, 7) stronger personal effort and commitment to established objectives, 8) more effective communications within the team and its interfaces, and 9) favorable schedule \& budget performance. Hence the correlation statistics validates analytically the basic proposition of this study that the organizational environment influences the team characteristics which influences team performance.

The team characteristics and project performance was measured as a perception of senior management (as discussed in the method section of this paper). The most significant associations point at the importance of professional esteem needs and managerial leadership as particularly favorable influences on project team performance. Specifically: 1) professionally stimulating and challenging work environments $[\tau=0.45], 2$ ) opportunity for accomplishments and recognition $[\tau=0.38], 3$ ) clearly defined organizational objectives relevant to the project $[\tau=0.36], 4)$ job skills and expertise of the team members appropriate for the project work $[\tau=0.36], 5$ ) overall directions and team leadership $[\tau=0.35]$, 6) trust, respect and credibility among team members and their leaders $[\tau=0.30], 7)$ business process, as reflected by cross-functional cooperation and support $[\tau=0.27], 8$ ) clear project plans $[\tau=0.25]$ and 9) clearly defined authority relations, and sufficient autonomy and freedom of actions in line with the managerial expectations and accountabilities $[\tau=0.23]$. While many of these factors, such as clear objectives, skill sets and effective business process deal with conventional project management practices, they also relate to the human side, conditioning the work environment for success. Hence in a complex project environment that relies on commitment, buy-in and personal drive for success, these influences appear to deal effectively with the integration of goals and needs between the team member and the organization. In this context, the more subtle factors seem to become catalysts for cross functional communication, information sharing, and ultimate integration of the project team with focus on desired results. All associations are significant at $p=0.1$ or better, with the most significant correlations $(p=0.01$ or stronger) shown in bold. To a lesser degree, opportunities for career development and advancement [ $\tau=0.12]$, as well as job security $[\tau=0.12]$, seem to have a positive influence.

\subsection{Cross-Correlation of Organizational Conditions}

Furthermore, the analysis provides a model for "per- formance projection". Project teams that are perceived by their management as effective in any one of these seven categories, such as innovation, change orientation, etc,are also seen as effective in many of the other seven categories, including efficiently utilizing time and resources, and leading to high overall project performance. While this finding is not surprising, it is interesting to see it statically validated. Specifically, we have tested the degree of cross-correlation among the performance variable of Table 1 via Kruskal-Wallis analysis of variance by rank. The test shows that managers agree on the ranking of team performance factors in the Table at a confidence level of $98 \%$. That is, managers who rate their team's performance high in any one of the performance variables are likely to give high ratings also to the other variables. This might indicate biases of managerial judgment, or just confirm the opinion expressed by several project managers that the same conditions in the work environment that are favorable to some type of performance, is also conducive to other types. This is clearly an area that would benefit from future research.

\subsection{Less Significant Conditions to Performance}

It is interesting to note that some characteristics of the work environmental, that were perceived by managers as important and influential to effective team performance, did not correlate significantly as measured by a p-level threshold of 0.10 . Others resulted even in negative correlations. As summarized in Table 1, the factors of lesser influence to project team performance are: (\#10) career development $[\tau=0.12]$, (\#11) job security $[\tau=$ 0.12], (\#12) Salary increases and bonuses $[\tau=0.15],(\# 13)$ time-off $[\tau=0.15]$, (\#14) project visibility and popularity $[\tau=0.12],(\# 15)$ maturity of the project team, measured in terms of time worked together as a team $[\tau=0.10]$. In addition, several conditions of the work environment actually correlated negatively to performance although they were seen by the majority of project managers as important positive drivers. As summarized in the table of this appendix, they include: (\#16) project duration $[\tau=$ $-0.08]$, (\#17) project requirements, stability and minimum changes $[\tau=-0.10]$, (\#18) stable organizational structures and business processes technological complexities, such as dependencies on multiple technologies, technological disciplines and processes, (\#19) technical complexity [ $\tau=-0.15]$, and (\#20) project size and project complexity, suggesting that project scope, size and implementation challenges, by themselves do not necessarily translate into lower team or project performance $[\tau=-0.18]$. Although the statistical significance of these "lesser associations (\#10 $\cdots \# 20)$ " is weak, it is interesting to observe that several of these influences actually seem to have opposite effects to those popularly 
held by managers. For example, it appears that increasing stability of project requirements seems to decrease overall project performance. While these correlations are nonsignificant from a statistical point of view, they are interesting because they run contrary to the perception held by the majority of managers. This might be indicative of the situational nature of these environmental conditions, with their influence varying from project to project, at least for certain conditions, such as $\# 10 \cdots \# 20$ shown in Table 1. These findings also help to shed additional light on the subtle and intricate nature of project team performance in technology-intensive environments. The current findings also raise new questions for future research.

\subsection{Additional Observations from the Field}

In addition to the quantitative data, information collected mostly during in-depth retrospective interviewing (Stage3 ) of this study, extend the findings further. Managers point out, that for today's technology-based projects, success is no longer the result of a few geniuses, experts and skilled leaders. Rather, project success depends on effective multidisciplinary efforts, involving teams of people and support organizations interacting in a highly complex, intricate, and sometimes even chaotic way. Especially for multi-national efforts, the process requires experiential learning, trial-and-error, risk taking, as well as the cross-functional coordination and integration of technical knowledge, information, and components. Many managers see the execution of their multi-national projects as part of a fuzzy process that cannot always be described linearly or planned perfectly, nor can results be predicted with certainty. Yet, in spite of all these challenges, many project teams work highly effective across international borders, producing great results within agreed-on budget and schedule constraints. This suggests that multi-national projects can be managed, given the right team environment and leadership. This observation is further supported by the statistical analysis of the field data of Stage-2 of this study which is summarized in the appendix. Specifically, the findings of the retrospective interviews and on-site observations from the action research of Stage-3 are integrated with the statistical results of Stage-2. This enables us to synthesize the field data, and to go beyond the conclusions gleaned from the statistical data summarized in the appendix. The combined inputs provide the basis for specific suggestions for leading and working effectively with culturally diverse project teams, discussed in the next section.

\section{Discussion and Managerial Implications}

One of the consistent and most striking findings from this field study is the need for increasing involvement and collective decision-making of all project stakeholders throughout the enterprise and its external partners. Project managers in our study point consistently at the reality that for today's complex and technology-based undertakings, success is no longer the result of a few expert contributors and skilled project leaders. Rather, project success depends on effective multidisciplinary efforts, involving teams of people and support organizations interacting in a highly complex, intricate, and sometimes even chaotic way. The process requires experiential learning, trial and error, risk taking, as well as the cross-functional coordination and integration of technical knowledge, information and components. Most managers see their projects evolving through a fuzzy transformation process which cannot always be described objectively or planned perfectly, nor can their results be predicted with certainty. Furthermore, project performance itself is difficult to define and measure. Yet, in spite of all of these challenges, many project teams work highly effective, producing great results within agreed-on budget and schedule constraints. This suggests that even complex multinational and technology-based projects can be managed toward agreed-on results, given the right team environment. Thus the field study provides some answers to the research objectives stated earlier, probing the influence of team leadership and organizational environment on project performance, and suggesting specific conditions that connect these variables.

\subsection{Lessons for Effective Team Leadership}

The empirical results presented in this paper show that specific conditions in the team environment appear most favorable to project team work. These conditions serve as bridging mechanisms, helpful in enhancing project performance, especially in complex project environments that involve technology and multinational settings. Therefore, managers must foster a work environment supportive to their team members. As shown by the statistical correlation, factors that satisfy personal and professional needs seem to have the strongest effect on the project team performance. The most significant drivers are $d e-$ rived from the work itself, including personal interest, pride and satisfaction with the work, professional work challenge, accomplishments and recognition. Other important influences include effective communications among team members and support units across organizational lines, good team spirit, mutual trust and respect, low interpersonal conflict, plus opportunities for career development and, to some degree, job security. All of these factors help in building a unified project team that can leverage the organizational strengths and competencies effectively, and produce integrated results that support the organization's mission objective. Creating such a 
climate and culture conducive to quality team-work involves multifaceted management challenges. Leading such self-directed teams can rarely be done "top-down," but requires a great deal of interactive team management skills and senior management support at the "local level" of the multinational team. Tools such as the Project Maturity Model and the Six Sigma Project Management Process can serve as a framework for analyzing and fine tuning the team development and management process.

\subsection{Managing Team Formation and Development}

No work group comes fully integrated and unified in their values and skill sets, but needs to be carefully nurtured and developed. Managers must realize the organizational dynamics involved during the various phases of the team development process. They must understand the professional interests, anxieties, communication needs, and challenges of their team members and anticipate them as the team goes through the various stages of its development. Many of the problems that occur during the formation of the new project team or during its life cycle are normal and often predictable. However, they present barriers to effective team performance and be quickly identified and dealt with before they impact project performance. Tools such as focus groups, interface charts and the Four-Stage Model of Team Development (originnally developed by Hersey and Blanchard, 1996), can help in identifying the leadership style and organizational support needed for facilitating effective team developments.

\subsection{Unify Management Process}

Successful management of geographically and culturally diverse project teams requires a unified managerial process. Unless these processes are integrated throughout the enterprise and aligned with the overall business strategy, technology transfer and project integration will not be effective. This does not mean rigid "top-down management" or "centralized operation," but rather a skillfully designed management system with enough flexibility and adaptability to local leadership while functioning consistently within established organizational norms and cultures. This is a big challenge for multinational companies. In part, it requires the ability to adapt project management tools, techniques and leadership to the local culture. That is, project success depends not only on the effective use of managerial tools and leadership style in one particular organizational environment, but equally important, on the effective use of these techniques across different geographic regions, without losing consistency and managerial integrity across the enterprise. This requires ef- fective working relationships among resource mana- gers, project leaders, and senior management across the whole project organization, and the skillful guidance of local management in collaboration with overall project leadership. Focus groups, organizational studies, internal and external consultants, process action teams, professsional training and teambuilding sessions, all are powerful tools for unifying and optimizing the work flow and managing process.

\subsection{Share Managerial Power and Influence}

Given the cultural differences and diversity across the multinational organization, power sharing among local managers and project integrators at headquarters is essential. Yet, a unified management process must exist with clear boundaries of authority, jurisdiction, responsibilities and decision making, as discussed in the previous paragraph, otherwise a power vacuum might develop, resulting in undesirable shifts of power, organizational conflict, power struggle and organizational tension. These power shifts are often predictable and come with early warning signs, such as communication issues, and confusion over command, control and authority, signaling that the managerial process is changing and requires finetuning. Tools such as focus groups, organizational studies, internal and external consultants, process action teams, professional training and teambuilding sessions, similar to those suggested for unifying the managerial process can be useful in creating awareness of the issues and challenges, and in allocating resources for organizational development of a unified framework for direction and leadership across the multinational enterprise.

\subsection{Aligning Enterprise Support Functions with the Project Management Process}

Projects, their work processes and support functions are imbedded within the enterprise system. Many of the supporting processes and functions, such as estimating, forecasting, progress measurements, purchasing, bid proposals, technology transfers, cross-functional communications and general managerial controls have their locus outside the project organization, controlled by senior management or administrative groups at headquarters. They affect the project environment with regard to resource availability, management involvement and support, personal rewards, and organizational stability, including goals, objectives and priorities. Effective project leaders understand the various organizational processes and the conditions that either help or hinder team performance. They can work with senior management to fine-tune these processes to best align with the project execution and to be most supportive to the team effort and overall project mission. Most importantly, effective 
team leaders at the top create a sense of community across the whole enterprise which is critical for unifying the team effort, especially in geographically dispersed multinational environments.

\subsection{Foster a Culture of Continuous Support and Improvement}

Culturally diverse teams are intrinsically complex, highly dynamic and continuously changing. By updating and fine-tuning established project management processes to changing conditions, team members feel empowered and unified by the relevant organizational environment. Management can establish "listening posts", such as discussion groups, action teams, and suggestion systems, that enable them to capture the voice of the customer as well as the lessons learned from past projects. This is the basis for continuous organizational improvements. Tools such as the project maturity model and the Six Sigma project management process can provide a useful framework for analyzing, developing and unifying project teams and their management processes.

\section{Conclusions}

In summary, the empirical results presented in this paper show that effective management of globally dispersed project teams involves a complex set of variables which relate to the organizational structure, business process, managerial tools, and most importantly, to the people in the organization and to the work itself. While many of the challenges show-up as technical problems, most of their root-causes can be tracked to social, psychological and organizational issues. In fact, we find consistently and measurably that people issues have the strongest impact on project performance. They affect many of the secondary performance variables, such as work process and managerial tools, because people are an intricate part of these subsystems, and issues affecting the people eventually impact the broader enterprise.

When integrated with a team of people with the right linkages and internal chemistry, this system can transforms resources, information and other inputs into tangible results. It can deal effectively with contemporary challenges, such as geographically dispersed workgroups, complex work integration, risks and non-linearity. However, success is neither automatic nor random! By examining the six

In particular, the field study shows that certain conditions related to the people side, such as personal interest, pride and satisfaction with the work, professional work challenge, accomplishments and recognition, appear most favorable toward unifying culturally diverse project teams and their work processes. These conditions serve as a bridging mechanism between organizational goals and personal interests, between central control and local management norms, and between following a project plan and adaptive problem solving. These are some of the conditions crucial to project success in complex multi-cultural organizations. However, achieving success is neither automatic nor random! Management cannot expect to create a unified project team, working seamless across borders and cultures, by simply issuing work orders, project summary plans or management guidelines. Emphasis must be on common values and goals, rather than on differences, to focus and unify the team. By recognizing the greater autonomy of all international partners as well as their cultural differences, management can build a true partnership among all the contributing organizations with strong linkages for communication, decision making and technology transfer. Also, higher level of transparency in terms of rewards and payoffs based on a cross-cultural understanding. Such a partnership is more likely to evolve if all team members throughout the project organization share the same objectives and commitments to desired results. To be sustainable, these multinational alliances must not only be built at the beginning of the project life cycle, but be refueled and maintained continuously over the lifetime of the project.

Effective project leaders are social architects who can foster a climate of active participation by involving people at all organizational levels in the planning, formation, and execution of projects. They also can build alliances with support organizations and upper management to ensure organizational visibility, priority, resource availability, and overall support for sustaining the team effort beyond its start-up phase. Accomplishing these conditions requires for project managers to developed effective skills in leadership, administration, organization, and technical expertise, and to engage top management throughout the project's life-cycle.

Taken together, this exploratory field study identifies some of the organizational conditions and managerial processes most conducive to high team performance in culturally-diverse multi-national project ventures. The findings should provide a framework to project managers and senior managers for benchmarking their enterprise environment and examining their management style and policies for creating the most favorable condition for team performance and success in multi-national project environments.

\section{REFERENCES}

[1] D. Armstrong, "Building Teams across Boarders," Executive Excellence, Vol. 17, No. 3, 2000, pp. 10-15.

[2] H. Barkema, J. Baum and E. Mannix, "Management Challenges in a New Time," Academy of Management Journal, Vol. 45, No. 5, 2002, pp. 916-930. 
doi: $10.2307 / 3069322$

[3] P. Dillon, “A Global Challenge," Forbes Magazine, Vol. 168, 2001, pp. 73-75.

[4] S. Chevrier, "Cross-Cultural Management in Multinational Project Groups," Journal of World Business, Vol. 38, No. 2, 2003, pp. 141-149. doi:10.1016/S1090-9516(03)00007-5

[5] J. Karlsen and P. Gottschalk, "Factors Affecting Knowledge Transfer in IT Projects," Engineering Management Journal, Vol. 16, No. 1, 2004, pp. 3-11.

[6] H. Thamhain, "Managing Innovative R \& D Teams," $R$ \& D Management, Vol. 33, No. 3, 2003, pp. 297-312. doi:10.1111/1467-9310.00299

[7] C. Ferrante, S. Green and W. Forster, "Getting More out of Team Projects: Incentivizing Leadership to Enhance Performance," Journal of Management Education, Vol. 30, No. 6, 2006, pp. 788-798. doi:10.1177/1052562906287968

[8] B. Groysberg and R. Abrahams, "Lift Outs: How to Acquire a High-Functioning Team," Harvard Business Review, Vol. 84, No. 12, 2006, pp. 133-143.

[9] R. Nellore and R. Balachandra, Factors Influencing Success in Integrated Product Development (IPD) Projects," IEEE Transactions on Engineering Management, Vol. 48, No. 2, 2001, pp. 164-173. doi:10.1109/17.922476

[10] D. Shim and M. Lee, "Upward Influence Styles of R \& D Project Leaders," IEEE Transactions on Engineering Management, Vol. 48, No. 4, 2004, pp. 394-413. doi:10.1109/17.969420

[11] A. Bhatnager, "Great Teams," The Academy of Management Executive, Vol. 13, No. 3, 1999, pp. 50-63.

[12] D. Cleland and L. Ireland, "Project Management: Strategic Design and Implementation," McGraw-Hill, New York, 2007.

[13] G. Cutler and R. Smith, "Mike Leads His First Virtual Team," Research Technology Management, Vol. 50, No. 1, 2007, pp. 66-69.

[14] M. Hilton, "Skills for Work in the $21^{\text {st }}$ Century," Academy of Management Perspectives, Vol. 22, No. 4, 2008, pp. 63-78. doi:10.5465/AMP.2008.35590354

[15] R. Keller, "Cross-Functional Project Groups in Research and New Product Development," Academy of Management Journal, Vol. 44, No. 3, 2001, pp. 547-556.

[16] J. Hackman, "Lading Teams: Setting the Stage for Great Performance-The 5 Keys to Successful Teams," Harvard Business School Press, Boston, 2002. doi:10.2307/3069369

[17] E. Kearney, D. Gebert and S. Voelpel, "When and How Diversity Benefits Teams," Academy of Management Journal, Vol. 52, No. 3, 2009, pp. 350-372. doi:10.5465/AMJ.2009.41331431

[18] M. Sawhney, "Don’t Just Relate - Collaborate," MIT Sloan Management Review, Vol. 43, No. 3, 2002, pp. 96-107.

[19] S. Sidle, "Building a Committed Workforce: Does What Employers Want Depend on Culture?" Academy of Management Perspectives, Vol. 23, No. 1, 2009, pp. 79-80. doi:10.5465/AMP.2009.37008007
[20] H. Thamhain and D. Wilemon, "Building Effective Teams in Complex Project Environments," Technology Management, Vol. 5, No. 2, 1998, pp. 203-212.

[21] D. Anconda and H. Bresman, "X-teams: How to Build Teams That Lead, Innovate and Succeed," Harvard Business School Publishing Company, Boston, 2007.

[22] J. Hackman, "The Five Dysfunctions of a Team: A Leadership Fable," Academy of Management Perspectives, Vol. 20, 2006, pp.122-125. doi:10.5465/AMP.2006.19873414

[23] I. Kruglianskas and H. Thamhain, "Managing Technology-Based Projects in Multinational Environments," IEEE Transactions on Engineering Management, Vol. 47, No. 1, 2000, pp. 55-64. doi:10.1109/17.820725

[24] E. Martinez, "Successful Reengineering demands IS/ Business Partnerships," Sloan Management Review, Vol. 36, No. 4, 1995, pp. 51-60.

[25] D. McFarlin, "Life Satisfaction Around the Globe: What Role Does Income Play?" Academy of Management Perspectives, Vol. 22, No. 4, 2008, pp. 79-80. doi:10.5465/AMP.2008.35590355

[26] E. McDonough III, K. Kahnb and G. Barczaka, “An Investigation of the Use of Global, Virtual, and Colocated New Product Development Teams," Journal of Product Innovation Management, Vol. 18, No. 2, 2001, pp. 110 120. doi:10.1016/S0737-6782(00)00073-4

[27] A. Jassawalla and H. Sashittal, "Building Collaborate Cross-Functional New Product Teams," The Academy of Management Executive, Vol. 13, No. 3, 1999, pp. 50-63.

[28] B. Sharma, "R \& D Strategy and Australian Manufacturing Industry: An Empirical Investigation of Emphasis and Effectiveness," Technovation, Vol. 23, No. 12, 2003, pp. 929-937.

[29] H. Thamhain, "Leadership Lessons from Managing Technology-Intensive Teams," International Journal of Innovation and Technology Management, Vol. 6, No. 2, 2009, pp. 117-133. doi:10.1142/S0219877009001595

[30] J. Solomond, "International High Technology Cooperation: Lessons Learned," IEEE Transactions on Engineering Management, Vol. 43, No. 1, 1996, pp. 69-78.

[31] H. Thamhain, "Managing High-Performing Project Teams in the Global Enterprise," Proceedings and Key Note Address of the 10th International Project Management Symposium (PMI), São Paulo, 13-15 September 2010.

[32] H. Thamhain, "Critical Success Factors for Managing Technology-Intensive Teams the Global Enterprise," Engineering Management Journal, Vol. 23, No. 3, 2011, pp. 30-36.

[33] H. Thamhain, "Criteria for Effective Leadership in Technology-Oriented Project Teams," In: Slevin, Cleland and Pinto, Eds., The Frontiers of Project Management Research, Project Management Institute, Newton Square, 2002, pp. 259-270.

[34] H. Thamhain, "Leading Technology Teams," Project Management Journal, Vol. 35, No. 4, 2004, pp. 35-47.

[35] H. Thamhain, "Team Leadership Effectiveness in Technology-Based Project Environments," IEEE Engineering Management Review, Vol. 33, No. 2, 2005, pp. 11-25. 


\section{doi:10.1109/EMR.2005.26743}

[36] H. Thamhain, "Optimizing Innovative Performance of R\&D Teams in Technology-Based Environments," Creativity Research Journal, Vol. 18, No. 4, 2006, pp. 435436.

[37] H. Thamhain, "Working with Project Teams," In: D. I. Cleland and L. Ireland, Eds., Project Management: Strategic Design and Implementation, McGraw-Hill, New York, 2007.
[38] B. Glaser and A. Strauss, "The Discovery of Grounded Theory: Strategies for Qualitative Research," Aldine, Chicago, 1967.

[39] K. Eisenhardt, "Building Theories from Case Study Research," Academy of Management Review, Vol. 14, No. 4, 1989, pp. 532-550.

[40] H. Thamhain, "Team Management," In: J. Knutson, Ed., Project Management Handbook, Wiley \& Sons, New York, 2001. 